\title{
Embodied Institutions and Epistemic Exclusions: Affect in the Academy
}

\author{
Millicent Churcher ${ }^{1}$ (D)
}

Accepted: 22 December 2021 / Published online: 11 January 2022

(c) The Author(s) 2022

\begin{abstract}
This paper explores the intersection between affect, emotion, social imaginaries, and institutions through the lens of epistemic power in the academy. It argues that attending to this intersection is critical for a fuller understanding of how affective and emotional dynamics can assist to entrench, but also disrupt, asymmetries of epistemic privilege that cut across lines of race, sex, and other markers of social difference. As part of this discussion the paper reflects on the possibility of intervening in dominant social imaginaries that become sedimented in the routine operations of the modern university, and which produce affective ecologies that sustain epistemic exclusions within academic institutions.
\end{abstract}

Keywords Epistemic power $\cdot$ Affect $\cdot$ Emotion $\cdot$ Social imaginaries $\cdot$ Institutions

At the 1985 Society for Phenomenology and Existential Philosophy (SPEP) conference, philosopher Sharon Meagher embarks on what she calls "her own informal campaign" to make her and her female colleagues "seen":

I approached women at the meeting, urging them to abandon their conservative conference attire (dark, conservative business skirt suits were the norm and expectation) in favour of clothes that they brought to go out in the evenings. I also encouraged women to take up as much physical space in conference rooms as possible. Many of us sprawled across chairs, putting our feet up. We asked lots of questions. Instinctually, we knew that we needed to resist the pressures to remain invisible. $(2012,204)$

At the time, Meagher realised that she and the other women present "had a real opportunity to capitalize on" the "newfound visibility" they had acquired thanks to the establishment of the SPEP Committee on the Status of Women the year prior (ibid.). Three decades on, Lewis Gordon - a distinguished professor of philosophy of Jamaican descent from the University of Connecticut — delivers his keynote address at the 2017 Australasian Society for Continental Philosophy. The conference is held in

Millicent Churcher

millicent.churcher@sydney.edu.au

1 Freie Universität Berlin, Habelschwerdter Allee 45, 14195 Berlin, Germany
Tasmania on stolen Indigenous land (lutruwita land). Before beginning his address, Gordon pauses and carefully removes his shoes-assuring his assembled audience that he means no disrespect in doing so. He speaks of the joy of experiencing having his toenails painted by his children, before launching into an expert analysis of Fanonian Phenomenology and Psychoanalysis; an analysis which he presents roaming and barefoot, without the use of notes or slides. During his talk, a woman with a newborn begins to make her way quickly to the exit after her baby starts crying. Gordon pauses mid-address and entreats her to stay: "Please," he says, "you don't have to leave. I have four children of my own, that sound is music to me."

This paper reflects on the significance of these embodied performances in relation to the connection between affect and emotion, social imaginaries, institutions, and epistemic power. Attending to how these phenomena interpenetrate is, on my view, critical for enabling a fuller understanding of how affective and emotional dynamics can assist to entrench, but also disrupt, arbitrary forms of epistemic privilege across lines of race, sex, and other markers of social difference. ${ }^{2}$

\footnotetext{
1 This record of Gordon's presentation was drawn from my own observations as an ASCP conference attendee. I am grateful to Anastasia Kanjere, another conference attendee, for providing additional details: https://acrawsa.org.au/2018/01/22/what-then-is-the-pathgrappling-with-resistance-and-complicity-in-the-academy/

${ }^{2}$ I use the terms emotion and affect interchangeably in this paper, although I acknowledge that theorists have drawn distinctions between these phenomena (see Slaby and Mühlhoff 2019). My account acknowledges the role of emotions like trust and esteem in
} 
This discussion focuses on the academy as an institution that is central to the global economy of knowledge production, and patterns of epistemic marginalisation within tertiary institutions. In pursuing this focus I develop the notion of the university as an embodied institution. An embodied institution is one whose set of norms, rules, and practices have evolved to serve the embodiment of those actors whose collective imaginings, attitudes, and attachments have had the power to shape (and reshape) the institution in question. ${ }^{3}$ As I will go on to explain, in academic settings this process of evolution produces ecologies of affect that can entrench and sustain epistemic exclusions, often in ways that are difficult to monitor and correct for. I argue that shifting these ecologies requires interventions at the level of Eurocentric, androcentric and other conservative imaginaries that tend to become sedimented in institutional norms, and which sustain overinvestments of trust and esteem in socially privileged knowers and epistemologies. As part of this discussion, I offer some examples of the concrete forms these interventions might take on in the space of the academy, paying close attention to the embodied practices of Gordon and Meagher and their disruptive potential. ${ }^{4}$

\section{Affect, Imaginaries, and Epistemic Praxis}

It is widely acknowledged that how we feel towards others will invariably influence how we receive their word: trust but also esteem, respect, and concern form part of a cluster of emotions that assist to facilitate knowledge sharing

\footnotetext{
Footnote 2 (continued)

guiding our epistemic practices, but also the influence of other kinds of affective phenomena that are less clearly defined and may not be appropriately accounted for in terms of emotions (phenomena including, for example, generalised anxiety and a sense of comfort and belonging).

3 This paper does not treat embodiment simply as a synonym for the body; rather, this term refers to intersubjective ways of being in the world that are marked by clustered imaginaries and affects. Embodiment necessarily emerges in and through one's experiences in specific socio-material settings, including institutional settings that embed particular imaginaries in their operations. My use of the term embodiment in this paper also intends to capture how epistemic exclusions are tied not only to biases in favour of embodied identities who share power and privilege, but also to how those bodies occupy and behave in social and institutional spaces.

${ }^{4}$ In exploring the disruptive and transformative potential of embodied practices that can expose and prompt reflection on conservative imaginaries and epistemologies, I acknowledge that these practices will take on a different shape and form depending on the actors who engage in them (e.g., their race, gender, ability, age, and so on) and according to the wider social and institutional context in which they act. What might have the capacity to 'break frame' and be constructive in one context may not achieve the same effect in another context. I am grateful to Joel Krueger and Jesse Prinz for drawing this point to my attention.
}

between persons (Candiotto 2019a). How we feel towards ourselves as epistemic subjects-for example, how disposed we are to feelings of intellectual self-trust and self-esteemimpacts our ability to meaningfully participate in practices of inquiry, communication, and deliberation.

On the view presented here, epistemic agency is deeply tied to how individuals imagine themselves in relation to their wider social context. Broadly speaking, the imagination enables individuals to make connections between objects of their immediate perception to experiences, images, and narratives that are embedded in memory. In bringing these psychically embedded experiences, images, and narratives to bear on the objects one perceives in the present, one's imagination works to invest those objects with a particular value, meaning, and significance that is affectively charged (Pillow 2009). ${ }^{5}$ The role played by imagination in perception means that it plays a key part in shaping how individuals register different epistemic subjects and diverse bodies of knowledge. In this context, one's imaginings structure affective attitudes and relations that influence one's habits of attention, deliberation, and evaluation, often without one's conscious awareness and reflective endorsement. Such habits can produce behaviours that run up against one's explicit beliefs and standing egalitarian commitments (Fricker 2007; Medina 2013). ${ }^{6}$

The human imagination is not a radically autonomous, individual capacity that is isolated from wider social influences; rather, it is conditioned by the stock of socially shared images, narratives, and other significations that are particular to a culture. These significations constitute the tacit and permanent backdrop against and through which collective human imaginings and feelings take shape (Celermajer et al. 2019). Within any given cultural context, shared imaginings of what or who is worthy of attention, respect, and emulation may be shaped by explicit theories and discourses, but they

\footnotetext{
${ }^{5}$ For a detailed account of what distinguishes imagination from perception, and the relationship between these capacities, see Kirk Pillow (2009). Pillow explains that the work of the imagination exceeds a capacity to mentally manufacture images of things that are not present to our immediate perception. Imagination plays an active role in perception by facilitating a form of 'seeing-as'. Seeing-as constitutes an "image-layering interpretive practice" (362) through which we perceive and experience objects as having a particular meaning and significance.

${ }^{6}$ The close nexus between imagination, feeling, and perception, and its role in shaping implicit judgements and behaviours that operate at a level below doxastic awareness, is well-documented by social epistemologists as well as theorists of implicit bias. Following Fricker (2007) and Medina (2013), my conceptual apparatus draws on the concepts of imagination, perception, and affect to explore the unconscious, embodied, and habitual character of our everyday epistemic practices.
} 
will also be shaped by clusters of images, narratives, myths, symbols, and metaphors that comprise the 'social imaginary' of that culture (Gatens 1996, 2004). ${ }^{7}$ As Moira Gatens points out, the concept of the social imaginary captures the idea that our relations with others and our wider environment "are more often sustained by social fictions of various kinds than they are by notions of "truth"' (2004, p. 282). As the following discussion elaborates, this is particularly clear with respect to the enduring influence that myths of women's inherent intellectual limitations and men's natural aptitude for higher-order thinking have on collective (and often unconscious) habits of overlooking women's academic contributions. To think of such myths as mere fabrications risks trivializing their significant power to shape patterns of sociability via their ability to engage faculties of imagination, perception, and feeling (Gatens 2004, ibid.). Through assigning differential visibility, meaning, and significance to particular ways of knowing and being in the world, social imaginaries work on habits of judgement and evaluation in ways that render certain voices and perspectives credible or incredible; intelligible or unintelligible. As Michèle le Doeuff notes, "there is no intellectual activity that is not grounded in an imaginary" (2003, p. xvi).

The images and narratives that comprise any given imaginary directly appeal to the imaginations of individuals, thereby shaping collective perceptions of one's environment

\footnotetext{
7 This paper distinguishes between imagination as an embodied capacity of individuals, and the social imaginary as the stock of ready-made significations that are particular to a culture. Following Moira Gatens (1996), I conceive of the social imaginary as shaping collective imaginings among members of that culture: that is, modes of imagining and perceiving the world in common with others. The 'imaginary' is a familiar concept within psychoanalytical, phenomenological, anthropological, and philosophical circles, and has been appropriated and developed in various ways. As Susan James explains, existing scholarship on the imaginary tends to be divided into two main camps: those who view it as an "individual psychic phenomenon which can be enhanced or damaged by the social environment," and those who take it to be "a social phenomenon which plays a role in the construction of individual subjectivity" (2002, p. 175). Those who fall within the former camp include Jacques Lacan and Drucilla Cornell, and those belonging to the latter include Cornelius Castoriadis, Michèle le Doeuff, Charles Taylor, and Gatens. This paper adopts a view of the imaginary as intrinsically social: following Gatens and others, it treats the imaginary as the tacit and permanent backdrop against and through which individuals come to imagine themselves as social actors in relation to others. Understanding the imaginary in this way does not imply that individuals cannot break free from the influence of dominant social imaginaries and imagine the world otherwise. On my view, a dialectic exists between an individual's lived experiences and the particular imaginary in which they are immersed. Just as the social imaginary structures an individual's lived experiences, so too may an individual's lived experiences spark critical reflection on this imaginary-especially the experiences afforded through embodied engagements with difference and through exposure to alternative imaginaries (see Sect. 3.0).
}

that are shot through with affect (Gatens 2004, p. 283). In this way, epistemic communities and practices are held in place not only by shared beliefs and convictions but also by shared affective investments and commitments that have their roots in wider social imaginaries. The social imaginary of a culture comprises multiple imaginaries-for example, sexual, racial, religious, economic, and political imaginaries-that tend to vary cross-culturally as well as historically (Gatens 1996). Social differences often give rise to competing imaginaries within a particular context that vie for legitimacy and authority. The shared experiences and perspectives particular to different racial, sexual, and other social identities have shaped (and have been shaped by) distinctive imaginaries, which have in turn structured divergent perceptions of what constitutes knowledge, how it is appropriately acquired, constructed, shared, and assessed, and who possesses it. These divergent perceptions are reflected in the distinctive epistemic practices of different cultural groups: for example, as Linda Tuhiwai Smith notes, academic research in the West remains governed by a British legal framework that, among other things, privileges the written text as "expert and research-based" over oral testimonies (2012, p. 46). In addition, this framework generally deems significant and credible those claims that are most widely known (Bignall et al. 2015, p. 8). These standards and practices sit in tension with Indigenous epistemologies and have ramifications for the perceived expertise and credibility of Indigenous Elders who are guardians of locally-based knowledge formations, and who typically pass this knowledge on through story-telling. In traditional Indigenous cultures, the more important a piece of cultural knowledge is, the more narrow its circulation tends to be. To share it publicly and widely would be to violate access privileges to knowledge that Elders bear sole responsibility for preserving and protecting (ibid.).

Owing to persistent inequalities of power between different social communities, the prevailing imaginary of any given culture will tend to confer an excessive degree of visibility, authority, and legitimacy on the voices, practices, and perspectives of powerful social groups who have enjoyed the privilege of shaping this imaginary, at the expense of those who have been excluded from processes of collective meaning-making and creation: including, for example, BIPOC, women, the working class, disabled persons, LGBTQI persons, and other identities that depart from a White, masculine, heteronormative, able-bodied, middle-class embodiment (Medina 2013). As the following section elaborates, this asymmetry of recognition manifests in part at the level of affect-particularly in the exclusion of marginalised social actors from networks of respect and esteem-and is reinforced by affective, bodily practices of various kinds. Such practices are mediated by the wider institutional settings in which they unfold. Affective disinvestments in ways 
of knowing and being that have been developed by marginalised social communities are often entrenched through normative institutional structures in which dominant social imaginaries become sedimented, and which systematically promote the epistemic standpoints and methodologies of those who share power and privilege. On the view presented here, institutions like the academy that are central to the production and dissemination of knowledge emerge from, and respond to, collective imaginings of certain voices and standpoints as epistemically valuable and authoritative, and function, in turn, to mediate shared habits of imagination and feeling that govern everyday epistemic practices. In other words, academic institutions are shaped by shared human imaginings and attachments, and serve to reproduce or refigure these imaginings and attachments (Celermajer et al. 2019). In what follows I attend to how relations of power get exerted and rendered productive in the academy through a broad range of mediated affective dynamics. ${ }^{8}$ As part of this discussion I explore how modes of emotional habituation and affective engagements in the space of the university assist to keep dominant epistemic cultures in place, and the kinds of emotive performances and rhetorical techniques employed by differently embodied actors to obstruct, as well as to galvanize, the formation of epistemic communities that are more diverse and genuinely inclusive.

\section{Embodied Institutions: Epistemic Exclusions in the Academy}

Modern institutions of education, including academic institutions, are broadly perceived as powerful correctives to the effects of racism, sexism, and other damaging social cultures. In part, this is because they enable individuals to be educated on terms of formal equality, and dispense important material benefits (including titles, honours, and rewards) that assist to endow their recipients with enhanced epistemic visibility and authority. However, this corrective function is compromised by the fact that academic institutions continue

\footnotetext{
8 This paper adopts a Foucauldian perspective of power as productive of particular subjectivities, as opposed to a conception of power as an external imposition on pre-formed human subjects. Yet it builds on this perspective by closely attending to the affective dimension of the productivity of power. In particular, this paper examines the specific ways in which the bodies of differently sexed and raced actors are experienced, imagined, and lived in academic institutions, and how dominant institutional structures condition emotional dispositions and affective practices that assist to keep these same structures in place. Yet I am not only concerned with the role of affect in stabilizing and maintaining existing arrangements: this paper also explores the potential for institutional actors to disrupt the disciplining effects of established norms and practices through affective and rhetorical performances (albeit in ways that are difficult to predict).
}

to embed and support the imaginings, attachments, and interests of those identities whom such institutions were historically designed to serve, and whose values and innovations have been decisive in shaping and reshaping normative institutional practices. On my reading, the university comprises a key example of an embodied institution that embeds particular imaginaries in its everyday operations, and which serves to (re)produce affective investments, relations, and practices that assist to maintain unearned forms of epistemic privilege. Despite popular notions of the university as a public domain of reason governed by an individualist, egalitarian ethic, its symbolic order is deeply masculinist and Eurocentric. ${ }^{9}$ This order has its roots in imaginaries that are firmly inscribed in the Western philosophical canon, and the twin dichotomies drawn therein between mind and body; reason and emotion; public and private; the universal and the particular. Within this scholarship, the devaluation of Black, female, and other non-normative bodies as innately closer to nature; as disorderly rather than orderly; as passionate rather than rational, is commonplace (le Doeuff 2003). Perhaps one of the most explicit expressions of an imaginary that embeds a hierarchical understanding of the masculine and feminine in terms of what the feminine excludes (rationality, universality, abstraction, autonomous thought) can be found in Hegel's Philosophy of Right:

Women are capable of education, but they are not made for activities which demand a universal faculty such as the more advanced sciences, philosophy and certain forms of artistic production. Women may have happy ideas, taste, and elegance, but they cannot attain to the ideal. The difference between men and women is like that between animals and plants; men correspond to animals, while women correspond to plants because their development is more placid and the principle that underlies it is the rather vague unity of feeling. When women hold the helm of government, the state is at once in jeopardy, because women regulate their actions not by the demands of universality, but by arbitrary inclinations and opinions. Women are educated - who knows how? - as it were by breathing in ideas, by living rather than by acquiring knowledge. The status of manhood, on the ... other hand, is attained only by the stress of thought and much technical exertion. (Hegel 2010 [1821], pp. 263-4)

Few would claim that the associations drawn by historical Western thinkers between maleness, rationality, abstraction,

\footnotetext{
9 As the following discussion illuminates, the exclusionary and unjust arrangements arising from this order are particularly pronounced in disciplines such as philosophy, economics, law, STEM fields, and the political sciences.
} 
and particular scholarly disciplines like philosophy and the 'advanced sciences' reflect the explicit attitudes and beliefs of contemporary academics. Nevertheless, the legacy of conservative masculine imaginaries continues to be felt in academic spaces, having become sedimented in the emotional, unconscious, and habitual dispositions of embodied actors (as well as in normative institutional structures, as I will come to explain). This anecdote from a female faculty member in philosophy captures a common experience for women in the discipline, who routinely report being denied the same recognition and attention as their male counterparts-especially at the micro-level of social interaction:

I have been fairly successful getting papers published, so that's not the problem. But this does not translate into respect or recognition at the conferences that I go to in my research areas. That is what has been irritating me lately. For example, I have attended X conference for 6 of the last 8 years. The conference is very specialized, and the review process for getting a paper on the program is highly competitive. Still, I manage to have a paper accepted regularly. Moreover, I am one of the most active participants in the conversation at the conference each year. I know everyone's name, as there are only about 50 of us. Despite all of this, several of the older male participants that make up the "base" of the society do not know my name. They do not bother to look up or share any biographical details when they present me. They do not read or cite my work. They have given leadership roles in the organization to male grad students over me, although I am now an Associate Professor. Those invited to give special papers at this conference are invariably picked among (a) a group of 5 or 6 core (older male) professors and (b) their male colleagues or male ("golden boy") students. ${ }^{10}$

As with the diminished visibility suffered by Meagher and her female colleagues, the above testimony demonstrates that formal modes of inclusion and recognition do not guarantee one's entry into informal and established communities of esteem. Gaining entry into such communities within a particular discipline such as philosophy is even less likely for marginalized philosophers working in non-traditional areas of research. Against the backdrop of an entrenched philosophical imaginary that associates knowledge with generality and abstraction, and which cast knowers as generic and interchangeable, scholarly concerns with particularity, embodiment, situatedness, power, and context appear both peripheral and subordinate to the pursuit of 'fundamental truths', which are uncovered through highly abstract and

$\overline{10}$ See https://beingawomaninphilosophy.wordpress.com/2018/05/15/ subtle-sexism-and-career-progression/ conceptual analysis (Gatens 1986). Against this symbolic backdrop, philosophers who focus on worldly concerns and who reflect upon the philosophical aspects of their lived experience frequently have their work discredited as subjective, emotive, and contingent as opposed to objective, neutral, and principled (Dodds and Goddard 2013. Also Tsosie 2017). Such experiences are, of course, not confined to philosophy (nor are they distributed equally across different academic disciplines). ${ }^{11}$ In the political sciences, the imagined separation between the private and public sphere makes itself felt in the continued lack of legitimacy and equal recognition accorded to scholarship that focuses on issues of race and gender, and the prevalence of state-centric, macrolevel analyses of political phenomena (Johnson 2014; Pearce et al. 2019). In the field of international relations as well as economics, analyses of institutional processes and institutional actors remain governed by a conservative, masculinist conception of individuals as homo economicus: as radically autonomous, disembodied, self-sufficient actors that act purely according to self-interest. This framework overlooks the reality of people's preferences and choices as being deeply shaped by their affective experiences and attachments, and by wider social relations and dependencies that often embed arbitrary inequalities of power.

In the academy, differential investments in the epistemic frameworks that have been developed by diverse social communities are reflected in the discursive construction of certain research areas as 'hard' or 'soft,' in ways that map on to the public/private, objective/subjective, masculine/ feminine, white/black divide (Johnson 2014). Black legal professor Jacquelyn Bridgeman recounts an incident where her colleague expressed a concern that in contrast to Bridgeman's other publications in legal theory, Bridgeman's work on issues of Black racial identity "did not demonstrate the kind of rigorous legal analysis" that Bridgeman's review board would count towards "a favourable tenure decision" (2020, p. 18. Emphasis mine). (The enduring purchase of imaginaries that privilege highly conceptual and abstract research as 'rigorous', 'technical', and 'hard' is part of what can help us to understand the significance of Lewis Gordon's performance, as I will come to explain.)

Conservative judgments of what constitutes research excellence in the academy, who is best placed to achieve it, and the affective relations that are bound up with these

\footnotetext{
11 This paper recognises that certain academic disciplines including anthropology and sociology have evolved to accommodate a more diverse range of voices and epistemologies (see Pearce et al. 2019 for an empirical account of the significant impact that feminist scholarship has had on knowledge production in sociology as compared with philosophy, economics, and political science). Addressing the question of why and how this evolution has occurred is an important task, but one that is beyond the scope of this paper.
} 
judgements are often entrenched by the everyday practices, norms, and arrangements of the corporate university that embeds neoliberal imaginaries in its operations. In particular, neoliberal imaginings of the individual as an agent in a free market competition with others, and as being accountable for their performance through systems of objective measures and quotas, inform normative practices, arrangements, and outcomes in academic contexts that compound the systemic disadvantages wrought by racist, sexist, and other damaging imaginaries. At the level of teaching, for instance, educators are rarely required or encouraged by their institutions to implement diverse curricula and pedagogies that are grounded in non-Western, non-androcentric epistemologies (Crouch 2012). At the level of research, hiring, promotion, and funding decisions continue to rely heavily upon quantitative publication data (for example, altmetric scores, journal weightings, and teaching scores), but often do so without critically attending to gendered, racial, and other biases in citation patterns, acceptance rates, and student evaluations (Pearse et al. 2019; Navarro 2017). The increasing casualisation of the university workforce coupled with the rollback of social support services (for example, affordable childcare and funding support for conference expenses) has seen economically disadvantaged identities and caretakers (who tend overwhelmingly to be women, and especially women of colour) become concentrated in insecure, low wage, teaching-intensive jobs, with economically advantaged groups (especially privileged White men) occupying more secure, highly paid, and research-intensive positions (Navarro 2017; Marchant and Wallace 2013). These material outcomes work to reinforce collective perceptions of White, male excellence, thereby assisting to sustain a warm and hospitable climate for dominant masculine identities in academia whilst at the same time leading others to feel alienated and out of place. The collective sense of belonging and comfort that is typically the preserve of elite males is often described as making itself apparent through the ways in which their bodies expand in academic and other social spaces: moving much more freely in a room than non-normative bodies, and taking up physical space unapologetically (Puwar 2004; Sullivan 2006). Resonant with Sara Ahmed's suggestion that "some more than others will be at home in institutions that assume certain bodies as the norm" (2012, p. 3) Meagher recalls receiving "puzzled looks" upon first entering the SPEP reception room, "as if I had just entered the men's locker room by mistake" (2012, p. 204). Her experience of being a body out-of-place at that time prompted her swift exit.

The structural reproduction of inflated investments in dominant ways of knowing and being works to endow dominant social actors with a strong sense of entitlement to dictate what is important, appropriate, and worthwhile in academic spaces. This affectively-charged posture can make itself felt through more explicit behaviours as well as through more subtle and spontaneous displays of incivility that include 'puzzled looks' as well as eye-rolling, sighing, and averted gazes (Ahmed 2012). These embodied gestures of disrespect are often mirrored by others who share power and privilege, owing to robust networks of allegiance and sociability. The fact that these behaviours occur at the microlevel of everyday social interaction makes them difficult for universities to regulate and control for.

Notably, marginalised social actors are not necessarily immune from the pull of dominant epistemic communities, and from emulating the practices of those who populate them. In this regard, institutionally embedded imaginaries can have a co-opting effect, further undermining networks of solidarity, trust, and concern among those whose specificity is not recognised and respected within the academy (Rich 1980). Being repeatedly exposed to embodied gestures of incivility in the absence of robust, countervailing solidarities can, over time, shape one's sense of self and epistemic agency in thoroughgoing ways. As Jan Slaby and Rainer Mühlhoff note, "affective relations over time both establish and subsequently modulate - make, unmake, remake-individual capacities and dispositions" (2019, p. 27). It follows, then, that repeated experiences of disesteem and disrespect from one's peers can readily crystallise into a standing disposition of self-doubt, thereby undermining one's willingness and capacity to participate in important epistemic pursuits (see Lambert et al. 2020). Patterns of self-exclusion among marginalised actors that are structurally coerced and affectively driven assist, in turn, to maintain a lack of epistemic diversity in academic communities. Against an image of the modern university as fair and meritocratic, this lack of diversity may simply be taken as an indicator that some identities more so than others are 'cut out' for the rigours of academic life.

\section{Embodied Interventions}

I have suggested that the embeddedness of conservative imaginaries in institutional norms and in the emotional, habituated dispositions of institutional actors gives rise to affective practices and encounters in the academy that enable and empower some subjectivities, whilst cramping and constraining others. These embodied dynamics help to keep dysfunctional institutional structures and epistemic exclusions in place.

The challenge of disrupting damaging affective ecologies that help to sustain unjust epistemic arrangements cannot be understated. Deep-seated feelings of disesteem, indifference, and other affective attitudes rooted in dysfunctional imaginaries are difficult to shift through standard mechanisms of education and factual contestation (Lennon 2010). 
Moreover, strengthened commitments to agendas of affirmative action and equality of opportunity may not be sufficient for combatting systematic epistemic exclusions wrought by embodied institutions like the academy. As noted earlier, academic institutions have evolved to serve a privileged masculine embodiment, and can all too frequently serve a powerful co-opting function that can undercut the affective solidarities and allegiances needed to support epistemic diversity in such settings.

Attending to the interlocking structure of social imaginaries, affect, embodiment, and institutions, and how this structure works to sustain arbitrary forms of epistemic power and privilege, illuminates the need for concurrent interventions at the level of collective social imaginings and their structural supports. If affective relations and dynamics are to support rather than undermine the conditions for just and inclusive epistemic communities to emerge, bringing counter-imaginaries and alternative knowledge bases from the periphery to the centre, and embedding them in everyday institutional operations, will be pivotal. On this view, the imaginaries of those who share power and privilege are not necessarily overdetermining. As Anna Hush notes, "the fact that dominant imaginaries are never universal or totalizing" permits "friction at the interstices of existing imaginaries" (2019, p. 145). Thus, "already existing insurrectionary imaginaries" offer a "productive opening for contesting dominant imaginaries" (ibid.). The elastic character of the imagination opens up the possibility for individuals to become invested in, and have their feelings shaped by, insurrectionary imaginaries that have been developed by epistemically marginalised communities (Medina 2013). Such imaginaries can be found in the work of various thinkers who have articulated, foregrounded, and developed alternative frames through which to understand the nature of knowledge and the knowing subject. Pamela Sue Anderson, Sabina Lovibond and A.W. Moore, for example, sketch an alternative philosophical imaginary that draws inspiration from the work of Maria Zambrano, Virginia Woolf, and le Doeuff. This counter-imaginary does away with Enlightenment dualisms (of mind/body; reason/passion) to symbolically cast the knowing subject as a "girl with a heart of reason" (2020, p. 16). Through challenging traditional associations of knowledge with the exercise of (White, masculine) disembodied reason, an imaginary of this kind lays the ground for investments of esteem and other recognitive affects to be established in relation to feminine and other marginalised ways of knowing and being that treat knowledge as inextricable from the feeling body. Promoting counter-imaginaries and new economies of affective recognition requires individual efforts as well as institutional shifts. At the individual level, subversive embodied practices on the part of institutional actors like Meagher and Gordon can support and enrich an alternative imaginary of who or what is worthy of epistemic esteem and respect. ${ }^{12}$ The embodied performances that Meagher and her colleagues conscientiously enacted during the 1985 SPEP conference were, in Meagher's words, "something akin to the strategy that we are taught to use when facing a bear in the wilderness, namely, to try to make ourselves appear larger than we actually are" (2012, p. 204). Through presenting an image of themselves as powerful, strong, and self-assured, and refusing to engage in embodied rituals that reflect and work to reinforce asymmetries of power (such as habits of 'shrinking' in traditional masculine spaces), Meagher and her colleagues rebel against the affective, behavioural logics that are tied to conservative masculine imaginaries. Their behaviour serves to disrupt an image of women as humble apprentices to male insight, and the unspoken expectations this frame produces (for example, implicit expectations that women will evince meekness, polite acquiescence, or deference in their encounters with elite male actors).

As noted above, the attempts made by Meagher and her colleagues to defy the assimilative pressures of the androcentric academy did not rely on the force of theoretical argumentation, but rather on affective, rhetorical performances: as Meagher reflects, through actively changing how their bodies occupied the conference space, "we all became the movement. And I ... learned what l'ecriture feminine (Holland 1990) meant in practice - we were all writing our bodies" (ibid. Emphasis mine). In a similar manner, Gordon challenges the gendered and racialised rituals that are common to the academy not merely through rational persuasion but through embodied praxis. Gordon occupies a senior post at a prestigious academic institution, yet his performance is atypical for an esteemed professor of philosophy: he first acknowledges his family; embraces a typical feminine ritual (of getting one's nails done); and encourages the presence of children in the room. Gordon's efforts work to destabilise the rigid, hierarchical dichotomies of hard/soft; masculine/ feminine; public/private; White/Black that govern normative practices in the academy. As a Black speaker addressing his (mostly White) audience barefoot, on colonised land, Gordon evokes an image that is associated with Indigeneity

\footnotetext{
${ }^{12}$ It is not my suggestion that members of marginalised communities bear primary or sole responsibility to resist the affective, behavioural logics that are encouraged by conservative imaginaries. Individual responsibility to intervene in patterns of epistemic marginalisation comes in degrees, and in accordance with the power and privilege one already happens to enjoy in a given context (see Medina 2013). Rebellious performances of the kind enacted by Gordon and Meagher may carry high costs for those who do not occupy positions of influence and seniority in the academy. On the view presented here, disrupting affective ecologies that assist to maintain the epistemic privilege of dominant actors also demands collective efforts to shift the institutional structures that reinforce these ecologies, such that the costs of individual resistance are mitigated.
} 
but also poverty and primitiveness in the Anglo-Australian imaginary. Gordon's prestigious status in the academy assists to disrupt this symbolic association. Furthermore, his confident embrace of conventions that are non-normative in the White academy presents a forceful challenge to Eurocentric imaginaries that strip Black and Indigenous cultures of epistemic prestige, credibility and legitimacy. In delivering a scholarly talk roaming and barefoot, and speaking of his children, Gordon enriches imaginaries that promote a perception of the knowing self as an embodied, feeling self; a self that is particular rather than abstract; as having a concrete history involving relationships and attachments to others, in contrast to mainstream imaginings of knowing subjects as detached, disembodied, and dispassionate informants. By presenting a forceful counter-image to such imaginings, Gordon's performance serves to carve out space for Black, Indigenous, and maternal bodies to enter into dominant communities of esteem on their own terms.

The dissonance wrought through performative efforts to 'break frame' can work to reveal and unsettle the unspoken and uncritical investments that even the most progressive and broad-minded actors may have in dominant epistemic cultures. Among committed actors, this experience of dissonance (and the feelings of embarrassment or shame it may induce) can initiate a process of reflective self-critique, which can, in turn, pave the way for shifts in one's habits of perception and feeling (see Candiotto 2019b). Yet if individual efforts to provoke collective reflection on the contingency and limitations of dominant epistemic arrangements are to spur a more thoroughgoing transformation of affective relations, the alternative imaginaries and knowledge bases promoted through such efforts must be widely institutionalized and socially supported (Medina 2013). This is especially in light of the potential for subversive acts-including those enacted by Meagher and Gordon-to generate pushback from powerful and particularly recalcitrant actors, and to engender a further entrenchment of existing and exclusionary arrangements. ${ }^{13}$ Pedagogical practices that move

\footnotetext{
13 Along with Braithwaite (1998) and Fricker (2013), I recognise the importance of efforts at the individual and institutional level to invest greater visibility and value in less dominant ways of knowing and being, and to encourage bottom-up processes of attitudinal change. Such efforts can assist to gradually establish a more robust 'institutional ethos' (Fricker 2013) with respect to recognising and accommodating diverse epistemic cultures, which can in turn help to mitigate or weaken backlash from institutional actors in response to important structural reforms. At the same, I do not intend to downplay or sideline the importance of mechanisms of accountability, surveillance, and penalization to mitigate disrespectful practices and to encourage conformance to standards of ethical practice. Alongside bottom-up strategies, these top-down mechanisms remain crucial for regulating the behaviour of dominant actors who greatly benefit from existing structures and who remain wedded to preserving them.
}

away from Eurocentric and androcentric norms of knowledge creation, sharing, and acquisition, and which embed culturally diverse norms of learning and communication in the design and delivery of teaching materials, comprise one example of an attempt to integrate marginalised imaginaries and knowledge bases within normative institutional praxis (hooks 1994; Paris and Alim 2017). So too does the implementation of research evaluation methods that eschew quantitative ranking systems or which would seek to incorporate new indicators into such systems based on feminist values of inclusivity and care (see Donovan 2019). Refiguring the very materiality of university settings, including what and who is recognised and honoured by the monuments, buildings, insignia, and other artefacts that are particular to a given institution also represents an effort to endow the intellectual achievements and histories of non-dominant groups with enhanced visibility and affective significance. By redistributing established patterns of epistemic visibility and salience, and through challenging sedimented imaginings of which epistemic traditions, practices, and pursuits are worthy of attention and emulation, institutional reforms of this kind can encourage the gradual creation of new economies of esteem, admiration, and respect. In doing so, they can work to prevent gestures of incivility (and other affective practices that cramp epistemic agency) from being widely reverberated. The effects of such reforms will be hard to predict from the outset. As Susan James explains, whilst coming to understand the workings of social imaginaries is a vital condition of change,

there is no recipe for success, no procedure for undermining or replacing particular images or their effects. In many cases, the task of modifying the way we understand ourselves and others, together with the way we feel, will be long and unpredictable, and will be achieved by imaginative techniques over which we have at best imperfect control. (2002, p. 187)

It is therefore important to remain vigilant with respect to the unforeseen consequences of shifting sedimented imaginaries, and to subject any new arrangements to careful, ongoing critique from multiple social perspectives.

\section{Conclusion}

Gatens notes that the close relationship between power, embodiment, and institutions requires us to "take account of the continuing presence of the past," and to interrogate how "our social and political institutions, the norms and 'rules of the game,' have developed historically in ways which take for granted a range of characteristics, in short, the embodiment of the individuals that those institutions 
were designed (or have 'evolved') to serve" (2002, p. 162). Institutions like the academy that have emerged against the backdrop of power imbalances between racial, sexual, and other social groups often serve to dispense unearned epistemic advantages to those whose embodiment they have evolved to serve. They do so in part by embedding dominant social imaginaries in their routine operations, which assists in turn to distribute recognitive affects of trust, respect, and esteem unevenly across lines of group difference. This evolutionary process and its bearing on collective emotional investments in particular knowers and epistemologies highlights the importance of attending to whose imaginings and attachments have enjoyed the power and authority to shape, and reshape, established epistemic practices, methodologies, and frameworks.

In this paper, I have suggested that the sedimentation of androcentric, Eurocentric, and other conservative imaginaries in institutional norms as well as in the habituated, emotional dispositions of institutional actors gives rise to shared attitudes and affective practices in the space of the academy that can reflect and reinforce relations of power between differently embodied identities, including arbitrary forms of epistemic authority and privilege. Reshaping the symbolic, material, and affective orders that interlock to dispense unearned epistemic advantages (and undeserved epistemic disadvantages) is a difficult task. In this context I have argued for the importance of interventions at the level of affective relations and practices, which need to be thought through in relation to the connection of these relations and practices to wider social imaginaries and their institutional supports. Reforming unjust epistemic dynamics necessitates targeting the embeddedness of damaging imaginaries within concrete institutions as well as in the affective commitments of institutional actors. Given that social imaginaries are lived in and through the body, it is primarily through embodied practices that their effects can be effectively resisted and interrupted. Subversive, embodied performances of the kind enacted by Gordon and Meagher require networked solidarity alongside the institutionalisation of alternative imaginaries and knowledge bases if such performances are to prompt meaningful shifts in collective habits of imagination, perception, and feeling. Having these conditions in place opens up the possibility for new affective relations and practices to be gradually established within the space of the academy, and lays the ground for more just and inclusive epistemic communities to emerge.

Acknowledgements The research for this paper was generously funded by the Alexander von Humboldt Foundation. I would like to thank the editors of this special issue, Laura Candiotto and Jan Slaby, as well as the two anonymous reviewers of this piece, for their constructive feedback and guidance. I am also grateful to Moira Gatens and to the participants in 'The Role of Emotions in Epistemic Practices and
Communities' workshop (Freie Universität Berlin 2021) for their valuable input on earlier drafts of this paper.

Funding Open Access funding enabled and organized by Projekt DEAL.

Open Access This article is licensed under a Creative Commons Attribution 4.0 International License, which permits use, sharing, adaptation, distribution and reproduction in any medium or format, as long as you give appropriate credit to the original author(s) and the source, provide a link to the Creative Commons licence, and indicate if changes were made. The images or other third party material in this article are included in the article's Creative Commons licence, unless indicated otherwise in a credit line to the material. If material is not included in the article's Creative Commons licence and your intended use is not permitted by statutory regulation or exceeds the permitted use, you will need to obtain permission directly from the copyright holder. To view a copy of this licence, visit http://creativecommons.org/licenses/by/4.0/.

\section{References}

Ahmed S (2012) On being included: racism and diversity in institutional life. Duke University Press, Durham

Anderson PS, Lovibond S, Moore AW (2020) Towards a New Philosophical Imaginary. Angelaki 25(1-2):8-22

Bignall S, Rigney D, Hattam R (2015) Colonial letters patent and excolonialism: forgetting, counter-memory and mnemonic potentiality. Borderl e-J 14(2):1-23

Braithwaite V (1998) Designing the process of workplace change through the affirmative action act. In: Gatens M, Mackinnon A (eds) Gender and institutions: welfare, work, and citizenship. Cambridge University Press, Cambridge

Bridgeman J (2020) Still I rise. In: Niemann YF, Gutiérrez Y, Gonzáles CG (eds) Presumed incompetent II: race, class, power, and resistance of women in academia. University Press of Colorado, Logan

Candiotto L (2019a) The value of emotions for knowledge. Palgrave Macmillan, Switzerland

Candiotto L (2019b) The virtues of epistemic shame in critical dialogue. In: Mun C (ed) Interdisciplinary perspectives on shame: methods, theories, norms, cultures, and politics. Lexington Books, Lanham

Celermajer D, Churcher M, Gatens M, Hush A (2019) Institutional transformations. Angelaki 24(4):3-21

Crouch MA (2012) Implicit bias and gender (and other sorts of) diversity in philosophy and the academy in the context of the corporatized university. J Soc Philos 43(3):212-226

Dodds S, Goddard E (2013) Not just a pipeline problem: Improving women's participation in philosophy in Australia. In: Hutchison $\mathrm{K}$, Jenkins $\mathrm{F}$ (eds) Women in philosophy: what needs to change? Oxford University Press, Oxford

Donovan C (2019) Do we need a feminist bibliometrics? In: Paper presented at the Excellenceand gender equality conference, Australian National University, Canberra, 26-28 June 2019

Fricker M (2007) Epistemic injustice: power and the ethics of knowing. Oxford University Press, New York

Fricker M (2013) Epistemic justice as a condition of political freedom? Synthese 190(7):1317-1332

Gatens M (1986) Feminism and philosophy, riddles without answers. In: Pateman C, Gross E (eds) Feminist challenges social and political theory. Allen \& Unwin, Sydney

Gatens M (1996) Imaginary bodies: ethics, power, and corporeality. Routledge, London 
Gatens M (2002) The politics of presence and difference: working through Spinoza and Eliot. In: James S, Palmer S (eds) Visible women: essays on feminist legal theory and political philosophy. Hart Publishing, Oregan

Gatens M (2004) Can human rights accommodate women's rights? Towards an embodied account of social norms, social meaning, and cultural change. Contemp Political Theory 3(3):275-299

Hegel F (2010) [1821] Philosophy of right, trans. Knox TM. Oxford University Press, Oxford

Hooks B (1994) Teaching to transgress: education as a practice of freedom. Routledge, New York

Hush A (2019) The imaginary institution of the university: sexual politics in the neoliberal academy. Angelaki 24(4):136-150

James S (2002) Freedom and the imaginary. In: James S, Palmer S (eds) Visible women: essays on feminist legal theory and political philosophy. Hart Publishing, Oregan

Johnson C (2014) Hard heads and soft hearts. Aust Fem Stud 29(80):121-136

Lambert MW, Wells MT, Cipriano MF, Sneva JN, Morris JA, Golightly LM (2020) Research culture: Career choices of underrepresented and female postdocs in the biomedical sciences. Elife 9:e48774. https://doi.org/10.7554/eLife.48774

le Doeuff M (2003) The sex of knowing, tr. Hamer K, Code L. Routledge, New York, London

Marchant T, Wallace M (2013) Sixteen years of change for Australian female academics: progress or segmentation? Aus Univ Rev $55(2): 60-71$

Meagher SM (2012) Feminist transformations. J Spec Philos 26(2):200-210

Medina J (2013) The epistemology of resistance: gender and racial oppression, epistemic injustice, and the social imagination. Oxford University Press, Oxford, New York
Navarro T (2017) But some of us are broke: race, gender, and the neoliberalization of the academy. Am Anthropol 119(3):506-517

Paris D, Alim SH (2017) Culturally sustaining pedagogies: teaching and learning for justice in a changing world. Teachers College Press, New York, London

Pearse R, Hitchcock JN, Keane H (2019) Gender, inter/disciplinarity and marginality in the social sciences and humanities: a comparison of six disciplines. Womens Stud Int Forum 72:109-126

Pillow K (2009) Imagination. In: Eldridge R (ed) The Oxford handbook of philosophy and literature. Oxford University Press, Oxford

Puwar N (2004) Space invaders: race, gender, and bodies out of place. Berg, Oxford

Rich A (1980) On lies, secrets, and silence: selected prose 1966-1978. Virago, London

Slaby J, Mühlhoff R (2019) Affect. In: Slaby J, Von Scheve C (eds) Affective societies: key concepts. Routledge, Abingdon, New York

Smith LT (2012) Decolonising methodologies: research and Indigenous peoples. Zed Books, London, New York

Sullivan S (2006) Revealing whiteness: the unconscious habits of racial privilege. Indiana University Press, Bloomington

Tsosie R (2017) Indigenous peoples, anthropology, and the legacy of epistemic injustice. In: Kidd IJ, Medina J, Pohlhaus G (eds) The Routledge handbook of epistemic injustice. Routledge, Abingdon, New York

Publisher's Note Springer Nature remains neutral with regard to jurisdictional claims in published maps and institutional affiliations. 